\title{
Diez años de gobierno del PSOE (1982-1992)
}

\author{
José María Marín Arce
}

\begin{abstract}
RESUMEN
El triunfo electoral del PSOE en 1982 abrió una dilatada época de gobiernos socialistas (1982-1996) que supuso la definitiva consolidación de la democracia, la integración en las instituciones europeas, la modernización de las estructuras sociales y económicas del pais y al mismo tiempo una profunda transformación de la sociedad española. Los primeros diez años de gobierno socialista constituyen la "edad dorada" del PSOE, cuando los distintos gabinetes presididos por Felipe González mantienen la iniciativa politica frente a una oposición débil y sin rumbo, y se llevan a cabo la mayoria de las politicas reformistas, en muchos casos forzadas por la presión de los sindicatos.

\section{PALABRAS CLAVE}

Socialismo, modernización, consolidación democrática, Felipe González, integración en Europa, referéndum OTAN, huelga general, Estado del bienestar.

\section{ABSTRACT}

The PSOE electoral victory in 1982 opened an extensive period of socialist governments (1982-1996) that supposed the definitive consolidation of democracy, the integration in the Europeans institutions, the modernization of the social and economic structures of the country, and at the same time an important tranformation of the Spanish society. The first ten years of socialist government constitute "the golden age" of PSOE. At this time the diferent governments that Felipe González leaded took the political initiative sacing a weak oposition without direction. In taht time they executed the most important reformist politics, in most of the cases forced by the press of the trade unions.

\section{KEY WORDS}

Socialism, Modernization, Democratic Consolidation, Felipe González, Integration in Europe, NATO Referendum, General Strike, Welfare State
\end{abstract}


Tras el proceso de readaptación ideológica del socialismo español, impulsado por los congresos de 1979 y 1981, el PSOE es ya un partido de centro izquierda, que ocupa una parte importante del espacio electoral de la UCD, cuando tienen lugar las elecciones generales de $1982^{\prime}$. Un partido moderado que se presenta a la confrontación electoral con el slogan «Por el cambio", que consistía -según palabras de Felipe González- en que España funcione. Algo que desde luego era importante pero que no significaba ningún tipo de transformación de las estructuras económicas o sociales. Ya se habian encargado los socialistas durante la campaña electoral de tranquilizar a lo que entonces se llamaba los "poderes fácticos". Ni la Iglesia, ni el Ejército, ni la Banca tenían nada que temer de un futuro gobierno socialista. Las nacionalizaciones se limitarían a la red eléctrica de alta tensión, la enseñanza privada continuaría recibiendo subvenciones, la Iglesia seguiria estando financiada por el Estado, y el gobierno apoyaría a los poderes financieros y protegería la economía de mercado ${ }^{2}$. Al mismo tiempo, el PSOE ofrecía a los electores un gobierno seguro y unido, capaz de consolidar la democracia, ampliar el marco de libertades, superar la crisis económica, construir el Estado de las Autonomías, terminar con el proceso de integración en Europa, íortalecer el sistema de partidos y afianzar la primacia del poder civil f́rente a las tentaciones golpistas. Es decir, desarrollar las políticas que habían iniciado los anteriores gobiernos de la UCD y que no habian podido culminar.

Este carácter centrista del PSOE, junto a la aplicación de una política que muy bien podría calificarse de liberal-progresista, van a marcar las dos primeras legislaturas del gobierno socialista. Habrá que esperar hasta 1989 para que se produzca un cierto giro socialdemócrata como fruto de las movilizaciones obreras que culminaron en la huelga general del 14 de diciembre de 1988. No es extraño, por lo tanto, que entre 1983 y 1988, la mayor oposición viniera de los sectores de izquierda, sobre todo de los sindicatos, y no de las fuerzas de la derecha.

\section{LAS ELECCIONES DEL CAMBIO Y LA PRIMERA LEGISLATURA SOCIALISTA}

El resultado de las elecciones generales celebradas el 28 de octubre de 1982 modificaron el mapa político español y supusieron un profundo

Comentarios de Edward Malefakis en Toms Burns MARAÑon: Conversaciones sobre el socialismo, Madrid, Plaza y Janés, 1996. pág. 275.

Santos JuliA: Los socialistas en la política española, 1879-1982. Madrid, Taurus, 1996, pág. 585 
cambio en el sistema de partidos que habia predominado durante la transición. Las anteriores elecciones de 1979 habian configurado un sistema en el que junto a dos partidos claramente mayoritarios, la UCD y el PSOE, ubicados en el centro del espectro político, existían otros dos, AP y PCE, situados en la derecha y en la izquierda respectivamente, que amenazaban con un pluralismo polarizado, que como apuntaba Giovanni Sartori empezaba a aproximarse peligrosamente al modelo italiano. Sin embargo, no se cumplió este pronóstico en las elecciones de 1982, cuyos resultados lo que provocaron fue un importante realineamiento en el sistema de partidos que afectó fundamentalmente a las fuerzas políticas de ámbito nacional. EI PSOE se convertía en hegemónico al conseguir más de 10 millones de votos y 202 diputados, lo que le daba holgadamente la mayoría absoluta en el Parlamento. El espectacular ascenso de la coalición AP-PDP, que superaba los cinco millones de votos y obtenía $106 \mathrm{di}$ putados, convertía a la derecha en el principal grupo de oposición. La UCD sufría un fracaso espectacular, perdía casi 5 millones de votos y con el 7,1\% de los votantes pasaba de 268 a 12 diputados. El PCE sufrió un profundo descalabro, perdió más de un millón de votos, apenas sobrepasó el $4 \%$ de los votantes y con sólo 4 diputados no pudo formar grupo parlamentario propio.

En el resto de formaciones políticas los cambios no fueron tan espectaculares. Los nacionalistas de CIU se beneficiaron del hundimiento de UCD en Cataluña, alcanzando los 12 diputados (8 obtuvo en 1979), y el PNV mantuvo su influencia electoral con 8 diputados. El Partido Socialista Andaluz (PSA) perdía sus 5 diputados y se convertía en extra-parlamentario; mientras Herri Batasuna conservaba dos, Euzkadiko Ezquerra mantenía uno y Esquerra Republicana de Cataluña, otro. Por último, la extrema derecha desaparecia del Parlamento y el CDS de Adolfo Suárez tenía que conformarse con sólo 2 diputados.

Al mismo tiempo se produjo la consolidación del bipartidismo (el PSOE y la coalición AP-PDP sumaban el $73 \%$ de los votos y el $88 \%$ de los diputados), sólo corregido por la consolidación de los partidos nacionalistas en Cataluña y el País Vasco. Era, sin embargo, un bipartidismo imperfecto en el que uno de los partidos, el PSOE, duplicaba en votos y en escaños a la derecha y se convertía en hegemónico no sólo en el Parlamento sino en la vida política española.

Para muchos españoles el triunfo del PSOE significaba la liquidación del franquismo y el verdadero final de la transición. Había sido posible la normalización política y la alternancia se había producido sin grandes sobresaltos, abriéndose un largo período de gobiernos socialistas, presididos 
por Felipe González, que abarcarían casi catorce años (1982-1996). Por primera vez en la historia contemporánea de España, un partido de izquierdas y de tradición obrerista iba a ocupar en solitario el poder, con el apoyo de más de diez millones de españoles, e iba además a conducir con éxito el proceso de modernización del país y la integración en las instituciones europeas.

Por fin España iba a estar gobernada por una joven generación de políticos -Felipe González tenía 40 años y la mayoría de los ministros rondaba esa edad - que no habian tenido vinculación con el régimen anterior y que estaban además muy alejados del recuerdo de la guerra civil. Este primer gobierno iba a suponer un cambio de rumbo en la política española, hasta entonces demasiado ligada al consenso entre las fuerzas parlamentarias y muy condicionada por el miedo al golpe militar. Afortunadamente en 1982 se habian conjurado los peligros involucionistas y los socialistas pudieron desarrollar un amplio programa de reformas de carácter administrativo, político, económico, social, etc, muchas de las cuales habian sido tímidamente iniciadas por los gobiernos de UCD.

Durante los primeros años de gobierno socialista, la derecha tuvo grandes dificultades para definir una política alternativa, optando la mayoría de las veces por desarrollar un tipo de oposición catastrofista que no respondía a la realidad del país ni a la percepción de una gran parte del electorado. Frente a la mayoría absoluta del PSOE, los grupos conservadores se empeñaron en una campaña de deslegitimación del gobierno, orientada a invalidar la capacidad legislativa de los socialistas, a los que acusaban de utilizar sistemáticamente el llamado «rodillo» parlamentario, como si el PSOE no pudiera traducir en leyes un programa electoral votado por más de 10 millones de ciudadanos. La estrategia parlamentaria de la coalición popular (AP-PDP-PL) fue claramente obstruccionista, sustentándose en la utilización abusiva del recurso previo de inconstitucionalidad, que sólo sirvió para retrasar el desarrollo de la Constitución, paralizando leyes tan importantes como la ley de libertad sindical (LOLS), la modificación de la ley orgánica del Tribunal Constitucional, la ley de despenalización parcial del aborto (modificación del Código Penal) y la ley orgánica del derecho a la educación (LODE). Fueron precisamente estas dos últimas leyes las que provocaron una importante corifrontación de los sectores sociales más conservadores contra el gobierno. La iniciativa y organización de la llamada "guerra" contra el aborto y la LODE corrió a cargo de diferentes grupos, ligados unos a los sectores más reaccionarios de la Iglesia - como la Asociación Nacional de Defensa de la Vida-, y vinculados otros con los propietarios de los centros escolares religiosos -CONCAPA, CECE, FERE - que se agruparon en torno a la Cocrdinadora por la libertad de 
Enseñanza. Sin embargo, estas movilizaciones, que duraron desde mediados de 1983 a finales de 1984, no fueron públicamente apoyadas por la jerarquía de la Iglesia, cuyo máximo organismo, la Conferencia Episcopal, mantuvo una discreta posición, favorable siempre a la negociación con el gobierno, puesto que la nueva ley no ponía en peligro el sistema de subvenciones a la enseñanza privada. Tampoco Alianza Popular demostró demasiado entusiasmo cuando se iniciaron las protestas, sólo se sumó a ellas en el momento en que percibió que podían ser utilizadas para desgastar al gobierno y para justificar la presentación del recurso de inconstitucionalidad. Quienes sí estuvieron desde el principio encabezando las manifestaciones anti-abortistas y anti-LODE fueron los dirigentes democristianos del PDP, partido integrado en Coalición Popular.

Quizás fue en el terreno de la Educación donde el gobierno procuró desarrollar con mayor fidelidad su programa electoral, produciéndose, en no mucho tiempo, cambios verdaderamente importantes tanto en la extensión y democratización de la enseñanza, como en la mejora y creación de centros públicos. Fue, además, en la política educativa promovida por los socialistas donde mayores diferencias podemos encontrar con la que los gobiernos de UCD intentaron desarrollar y no pudieron, puesto que la ley orgánica del Estatuto de Centros Escolares (LOECE), claramente favorecedora de la enseñanza privada, fue parcialmente declarada inconstitucional a principios de 1981.

En el resto de las políticas sectoriales apenas hubo confrontación entre la derecha y el gobierno, fundamentalmente, porque fueron en gran medida continuación de las iniciadas por los anteriores gobiernos de UCD.

En las grandes decisiones referidas al desarrollo autonómico, el partido socialista mantuvo el consenso entre los dos grandes partidos de ámbito estatal, tal y como había sucedido durante los años de la transición. En 1981, el PSOE había pactado con UCD la LOAPA, y cuando esta ley orgánica, en agosto de 1983, es declarada inconstitucional en muchos de sus artículos, el gobierno socialista promueve la ley del proceso autonómico, mucho más limitada y que no consigue impulsar el acuerdo con los partidos nacionalistas. Durante la primera legislatura, el partido socialista dirigió su política autonómica en tres direcciones. En primer lugar, terminar con la aprobación de los Estatutos de Autonomía que todavía quedaban pendientes (Extremadura, Baleares, Madrid, Castilla y León). En segundo lugar, dotar a las comunidades autónomas de los medios humanos, técnicos y financieros para impulsar de una forma real el proceso de autogobierno, respetando en lo fundamental la ley de financiación de las comunidades autónomas (LOFCA), vigente desde septiembre de 1980. Y en tercer lugar, 
desarrollar los traspasos de competencias a las comunidades autónomas. La resistencia del partido socialista a aceptar los niveles de autogobierno reclamados por los partidos nacionalistas dificultó enormemente las negociaciones de los traspasos y provocó una extraordinaria conflictividad entre el gobierno central y los gobiernos autonómicos del País Vasco y Cataluña, que optaron por recurrir sistemáticamente al Tribunal Constitucional, ralentizando y dificultando el proceso autonómico.

A finales de 1986, cuando Joaquín Almunia reemplazó a Javier Moscoso al frente de la cartera de Administraciones Públicas, habían terminado ya prácticamente los traspasos a las comunidades autónomas y comenzaba un periodo de cierta armonía con los nacionalistas vascos y catalanes. Los problemas surgieron entonces con las comunidades que habian optado a la autonomía por la vía del artículo 143 de la Constitución y que comenzaron a solicitar la reforma de sus estatutos para poder tener las mismas competencias que las comunidades llamadas «históricas», que habian utilizado el artículo 151. Esta reivindicación fue recogida por el PP y por el PSOE en el pacto autonómico que Felipe González y José María Aznar firmaron en febrero de 1992, reanudándose el consenso entre los grandes partidos nacionales que había dominado la política autonómica desde la aprobación de la Constitución. Esta política de consenso se rompió durante la última legislatura socialista, cuando el PSOE necesitó los votos de CIU, PNV y Coalición Canaria, y el Partido Popular reaccionó acusando al gobierno de favorecer el separatismo a cambio de los apoyos parlamentarios de sus socios nacionalistas.

La política antiterrorista respecto a ETA fue muy similar desde los comienzos de la transición hasta los años noventa. Tanto los gobiernos de la UCD como los del PSOE aplicaron, si bien con distinto énfasis, dependiendo de las circunstancias, las mismas líneas maestras en su lucha contra el terrorismo etarra, dirigidas fundamentalmente a: 1) Buscar la colaboración con Francia para terminar con la extraordinaria permisividad que las autoridades francesas nabian tratado a ETA durante el franquismo, permitiendo que en su suelo tuvieran su "santuario", desde donde organizaban sus acciones en España con total impunidad. 2) Aplicar una política de reinserción de los presos etarras que abandonaran la lucha armada e intentar abrir vías de negociación con ETA para lograr cuanto antes la pacificación de Euskadi. 3) Continuar con las medidas de represión a través del reforzamiento de la legislación antiterrorista y de la acción de las fuerzas de seguridad del Estado, cuyos mandos fueron mantenidos por el PSOE en 1982.

Tampoco en el desarrollo de la política exterior hubo importantes discrepancias entre el PSOE y la derecha. Ni en la marcada orientación 
occidentalista que se impuso en el PSOE tras las elecciones de 1982, ni en las difíciles y largas negociaciones para la integración en la Comunidad Europea. Sólo con respecto a la OTAN se produjeron divergencias, no sobre el fondo de la cuestión, puesto que los grupos de Coalición Popular eran profundamente pro-atlantistas, sino sobre los términos en que se planteó el referéndum, aunque, en realidad, la derecha lo único que pretendió fue utilizar la consulta popular para desgastar al gobierno y sacar tajada electoral de un posible fracaso del PSOE. Por el contrario, el cambio de postura de los socialistas respecto a la Alianza Atlántica se convirtió en uno de los ejes más importantes de la oposición de izquierdas. Una oposición, con escasa representación parlamentaria, que tuvo que recurrir a la movilización popular en un intento de articular políticamente el sentimiento anti-atlantista de una parte importante de la población.

EI PSOE, cuando accedió al poder en 1982, se encontraba en una difícil situación respecto a la OTAN. En primer lugar, la posición oficial del partido (29 Congreso del PSOE de 1981) era propiciar la salida de la Alianza. En segundo lugar, el PSOE había encabezado las movilizaciones de 1981 contra la decisión del gobierno de UCD de «meternos en la OTAN por la puerta de atrás", y había hecho del slogan "OTAN, de entrada NO" uno de los reclamos más importantes de la campaña electoral de 1982, prometiendo la celebración de un referéndum para decidir la salida de la Alianza. En tercer lugar, el antiamericanismo era un sentimiento mayoritariamente compartido por la izquierda y la lucha contra la política de bloques había sido un elemento movilizador tanto de las organizaciones pacifistas como de los partidos de izquierda. Pero, cuando el PSOE gana las elecciones de 1982, el nuevo gobierno socialista enseguida se da cuenta de que no era conveniente, ni incluso posible, la retirada de la Alianza, pues como decía Fernando Morán, ministro de Asuntos Exteriores, "los partidos que acceden al poder deben asumir las obligaciones internacionales contraídas por los gobiernos precedentes para evitar la inestabilidad". Pero, Felipe González, en vez de abordar directamente el problema, respetando la decisión tomada por Calvo Sotelo, se decidió por impulsar una política dilatoria, que algunos autores han calificado de «ambigüedad calculada", que le permitiera cambiar primero la posición del gobierno, después la del partido para finalmente buscar el momento más propicio de convocar el prometido referéndum.

Durante los primeros años de legislatura, el gobierno fue progresivamente modificando su posición inicial, a través de continuas declaraciones en la prensa cada vez más favorables a la permanencia en la Alianza, y en el seno del Consejo de Ministros terminaron triunfando las posiciones más pro-atlantistas, defendidas sobre todo por Narcis Serra. Sin embargo, no 
hubo una clara definición sobre la OTAN hasta octubre de 1984, cuando Felipe González presentó en el Congreso su decálogo sobre política exterior en el que se proponía la permanencia en la Alianza, sin integración en el mando militar, con la decisión de la no nuclearización de España y renegociando el establecimiento de las bases nortemericanas.

Tras el fin de la ambigüedad del gobierno respecto a la OTAN, el siguiente paso era conseguir el apoyo del partido, que de acuerdo con las resoluciones del último congreso seguía defendiendo las tesis contrarias a la permanencia en la Alianza. No fue fácil convencer a la militancia socialista, que con tanto ardor se había movilizado en 1981 contra la OTAN, de la necesidad de apoyar la permanencia en la Alianza. La dirección del PSOE, y muy especialmente Felipe González, tuvieron que emplearse a fondo en los debates del 30 Congreso del PSOE, celebrado en diciembre de 1984, para conseguir aislar a los partidarios de la salida de la OTAN. Como cabía esperar, la dirección del partido ejerció un control sobre el congreso bastante eficaz. Sin embargo, no pudo evitar que se produjera una importante división entre los delegados que se reflejó tanto en la dureza de los debates como en el resultado de las votaciones que a lo largo del congreso fue evolucionando hacia las tesis oficiales, debido en gran parte al relevante papel de Felipe González, que intervino personalmente en algunas comisiones, como la de exteriores, donde salvó "in extremis" una votación que de antemano se preveía contraria a la OTAN.

Una vez conseguido el apoyo del partido, había que convencer al electorado de la necesidad de mantenerse en la Alianza. Felipe González, además de referirse a la responsabilidad española en la defensa y seguridad europeas y rechazar el neutralismo, argumentos que ya habia utilizado el centro-derecha, centró su discurso en señalar las consecuencias que tendría para España una eventual salida de la Alianza: sería un factor de inestabilidad interna e internacional, en la medida en que se pondría en entredicho nuestra credibilidad al romper los compromisos establecidos por gobiernos anteriores; provocaría una alteración de los equilibrios establecidos, contribuyendo a debilitar políticamente a la Alianza, y el último lugar, se vería comprometida la participación española en el proceso de construcción europea. Aun sin decirlo explícitamente, esta última consideración estaba directamente relacionada con el propósito de integración en la Comunidad Europea

Este intento de vincular la presencia en la Alianza con el proceso de integración en la CE fue permanentemente utilizado por los dirigentes socialistas durante los años que duró el debate sobre la OTAN. Esta vinculación fue hábilmente manejada, dependiendo del momento y de a quién 
se pretendía presionar. Por una parte, se trataba de convencer a los españoles de que no era posible participar en la Europa económica sin contribuir en la defensa común. Es decir ¿cómo se podía solicitar la entrada en la CEE si existía el proyecto de retirarse insolidariamente de la OTAN? Este fue uno de los argumentos más importantes que se emplearon para justificar el cambio de posición del gobierno. Ya en mayo de 1983, Manuel Marín, secretario de Estado para las Relaciones con la CEE, afirmaba que la indecisión y la ambigüedad española respecto a la OTAN dificultaba las negociaciones con la Comunidad, pues algunos paises europeos, especialmente la RFA, estaban especialmente interesados en que España no rompiera sus vínculos con la Alianza. También Felipe González utilizaba parecidos argumentos, aunque era Narcis Serrra quien con mayor contundencia establecia esta relación, añadiendo además las repercusiones que una eventual retirada de la OTAN tendría para el desarrollo de nuestra industria e incluso para la consolidación de la democracia.

Por otra parte, el gobierno intentaba convencer a los países europeos de la necesidad de acelerar las negociaciones comunitarias, pues de ello dependía en gran medida cambiar la mayoritaria opinión anti-atlantista de la población. Felipe González, cada vez que había problemas importantes que retrasaban la negociación con la CE, agitaba el espantajo de la OTAN como medio de presión, pues "¿cómo pedir a los españoles -afirmaba Manuel Marín- que sigan en la OTAN si no se les integra en la CE?".

Una vez firmado el tratado de adhesión a la CE, en junio de 1985, el gobierno decidió la convocatoria del referéndum, que se celebró el 12 de mayo de 1986 y cuyos resultados (el $52.3 \%$ votó afirmativamente, el $39,8 \%$ optó por el NO, y la abstención, promovida por Coalición Popular, fue del $40,45 \%$ ) supusieron un gran triunfo tanto para Felipe González como para el PSOE, que consiguió ganar nuevamente las elecciones legislativas de 1986. Sin embargo, a largo plazo el desarrollo del referéndum fue un factor de erosión del partido socialista. Destacados dirigentes socialistas, como Narcis Serra o Joaquín Almunia, años más tarde reconocieron que fue un clarísimo error tanto la férrea oposición que en 1981 mantuvieron a la entrada en la OTAN como la posterior convocatoria del referéndum ${ }^{3}$.

Si algo enturbió la vida política durante estos años, exasperando tanto a la oposición de izquierdas como a la de derechas, fue más el tema del referéndum que el hecho de que el gobierno y el PSOE hubieran cambiado

3 Tom Burns marañón, op. cit. págs. 191 y 314. 
de postura. Tanto su aplazamiento sistemático, durante más de tres años, como la indefinición sobre su carácter vinculante o consultivo, así como el confusionismo de la pregunta sometida a consulta, la falta de apoyo al gobierno por parte de la derecha y los nacionalistas, y sobre todo el desarrollo de la campaña, hicieron del referéndum el tema más controvertido de la política nacional de aquellos años.

\section{EL ENFRENTAMIENTO CON LOS SINDICATOS. DE LA RECONVERSIÓN INDUSTRIAL A LA HUELGA GENERAL DEL 14-D}

Además de las movilizaciones contra la OTAN, hubo una fuerte oposición sindical contra la política de reformas liberalizadoras en el terreno de la economía que habían ya comenzado durante los gobiernos de la UCD y que el PSOE tuvo inevitablemente que culminar. El imprescindible saneamiento de la economía, el comienzo en serio de la reconversión industrial, con la consiguiente pérdida de puestos de trabajo, el adelgazamiento y reforma del sector púb!ico, la contención de los salarios, el abandono del Estado providencia, comprendian medidas de ajuste tan duro, que sólo podían ser aplicadas por un partido como el PSOE que en aquellos momentos gozaba de una gran autoridad moral sobre las capas sociales más desfavorecidas ${ }^{4}$. Sin embargo, la escasa predisposición del gobierno al diálogo con los sindicatos y las actitudes excesivamente desafiantes de los ministros de Economía e Industria condujeron al enfrentamiento con las centrales sindicales y provocaron un rosario de luchas obreras, primero contra la reconversión industrial y más tarde contra la política económica, que condujeron a la huelga general del 14 de diciembre de 1988.

Cuando los socialistas llegaron al poder en octubre de 1982, se encontraron con unos planes de reconversión sectorial, aprobados en 1981, que prácticamente no habían entrado en vigor y que además no eran suticientemente avanzados para resolver definitivamente los graves problemas de la industria española ${ }^{5}$. Era necesario reducir aún más las plantillas, disminuir la capacidad productiva de sectores como la siderurgia integral y la construcción naval, y además comenzar a reestructurar un conjunto de sectores, como la automoción, los fertilizantes, electrodomésticos, bienes de

4 Gregorio VALdelVIRA GONZALEZ: “Las ondas largas de la política en el siglo xx" en Espacio. Tiempo y Forma, Madrid, UNED, 1998.

6 José María MARIN ARCE: Los sindicatos y la reconversión industrial durante la transición. 1976-1982. Madrid, CES, 1997. 
equipo, maquinaria eléctrica, etc. que aunque habian sido incluidos en los planes de reconversión apenas si se habian modificado.

Las líneas maestras de la reconversión propuestas por el Ministro de Industria, Carlos Solchaga, aparecieron en mayo de 1983 en el Libro Blanco de la Reindustrialización. En resumen, se trataba de reordenar los sectores en crisis, redimensionar su capacidad productiva, llevar a cabo una importante reducción de plantillas y además sanear financieramente las empresas para que cuanto antes se pudiera comenzar con las inversiones productivas. Para todo esto, era necesario recurrir a los fondo públicos, pues ni los gobiernos de UCD, ni los del PSOE pudieron conseguir implicar al capital privado en los procesos reconversores. Sólo logró Solchaga imponer a la Banca un coeficiente de inversión obligatorio destinado a la reconversión. Lo que no hizo el gobierno socialista fue recurrir a las nacionalizaciones, como habian hecho los gobiernos de UCD. Ya en el programa electoral del PSOE se renunciaba a la política de socialización de pérdidas que había tenido lugar de 1975 a 1981.

EI PSOE, en la oposición, había criticado la falta de una política industrial coherente por parte de los sucesivos gobiernos de la UCD, proponiendo, en numerosas ocasiones, la elaboración de una serie de planes de reconversión y reindustrialización con el acuerdo de los sindicatos. Por ejemplo, desde la páginas de «El Socialista» reconocidos economistas del PSOE, la mayoría integrados en el llamado grupo "Alihiers", hicieron continuos llamamientos a la concertación durante los años 1979 a 1982. Sin embargo, el primer gobierno del PSOE no llevó a cabo ningún intento serio de concertación con los sindicatos en la planificación de la política industrial. Ni el RD de julio de 1983 sobre inversiones básicas en la siderurgia integral, ni el RDL de noviembre de 1983 de reconversión y reindustrialización, ni la posterior ley de reconversión de julio de 1984, fueron negociados con los sindicatos, contando por lo tanto con la oposición de los mismos, incluido UGT, y también con la oposición del resto de las fuerzas políticas. Este empeño del gobierno en llevar adelante el proceso de reconversión "con decisión» y con «rigor», según palabras del Ministro de Industria, provocó un importante crecimiento de la conflictividad laboral, que tuvo sus inicios en febrero de 1983, cuando se anunció el desamantelamiento de los Altos Hornos de Sagunto, y que no remitiría hasta 1989.

En realidad, los mayores problemas no se derivaron del planteamiento general sobre la reconversión, sino de cómo se abordaba la reducción de plantillas y de las reticencias del Ministerio de Industria a la hora de negociar con las centrales sindicales. En los primeros momentos, el gobierno pensó que sólo con el apoyo de la UGT podía sacar adelante los proyectos 
de reconversión tal y como habian sido elaborados por el ministro de Industria, pero la fuerte presión de los trabajadores y la oposición de CCOO hizo que progresivamente dichos planes se fueran flexibilizando en temas como la regulación de plantillas. El propio Solchaga reconocía que al final tuvo que ceder, no pudiendo doblegar a los sindicatos.

"Se trataba -decia Solchaga- de elegir entre lo malo y lo peor y creo que elegimos lo primero. Es cierto que la instrumentación de los planes de reconversión no se hizo exactamente sobre las pautas de extinción de contratos de trabajo de los excedentes laborales que yo había defendido y que no sólo hubieran ahorrado dinero a los contribuyentes sino que, además, hubieran supuesto un aviso para los sindicatos sobre el coste de mantener posturas rígidas en materia de ajuste industrial en momentos de grave crisis ${ }^{6} "$.

En el apoyo de la UGT a los planes de reconversión no sólo había motivos de carácter político sino también motivaciones referidas a la estrategia sindical. Además de la fuerte vinculación de la UGT con el PSOE, la dirección del sindicato pensaba que le era muy rentable continuar con esa imagen negociadora, que había comenzado con la firma del AMI a principios de 1980 y tan buenos resultados le había dado en las elecciones sindicales de 1982, y que esta política podía ser también un elemento para aislar aún más a CCOO. Los dirigentes de la UGT tenían la confianza de poder negociar efectivamente con el Ministerio de Economía y de Industria. Pero, la verdad es que el gobierno no estaba dispuesto a negociar con nadie su política económica. El propio Carlos Solchaga explicaba que "los sindicatos no podían condicionar la política económica y que el gobierno no debía estar sometido a ellos como le había sucedido al gobierno laborista con los Trade Unions" ? . Llevando hasta el extremo esta interpretación, el gobierno tampoco debía estar condicionado por el partido. Una de las principales controversias en el seno del PSOE estuvo basada en la distinta interpretación sobre el papel del partido y del gobierno en la configuración del proyecto socialista. En resumer, el debate se centraba en quién debía mandar. Si era el partido, junto a! sindicato, quienes debian marcar sus criterios al gobierno, siendo fieles a la tradición de izquierdas del socialismo, postura mantenida tanto por Nicolás Redondo como por Alfonso Guerra, aunque éste con matices. $O$, por el contrario, debia ser el gobierno quién decidiera las líneas maestras de su política, buscando únicamente su ratificación por el partido. Esta última posición, defendida por Felipe González, fue la que

Carlos Solchaga: El final de la edad dorada, Madrid, Santillana, 1997, págs. 56 y 57.

Tom BURNS MARANON, op. cit. pág. 152. 
finalmente triunfó, no sin dificultades y desgarros internos, sobre todo a partir de la salida de Alfonso Guerra del gobierno.

La mayoría de los dirigentes de la UGT, encabezados por Nicolás Redondo, no llegaron nunca a aceptar que el gobierno socialista, por una parte les pidiera apoyo y fidelidad, y por otra, les negara cualquier tipo de participación en la elaboración de la política económica y, por supuesto en los planes de reconversión. Así es que, cuando se dieron cuenta de que el gobierno sólo pretendía utilizar al sindicato para que firmara los planes de reconversión y no para negociar la política industrial, y mucho menos la política económica, fueron progresivamente marcando distancias con el gobierno.

Al mismo tiempo, la UGT comenzó a percibir que su política de apoyo incondicional a los planes de reconversión iba minando su influencia entre los trabajadores y también entre sus afiliados. Su postura fue cambiando a medida que pasaban los meses y no se creaban puestos de trabajo alternativos para los trabajadores excedentes. Ya desde comienzos de 1985 , empezó a sumarse a las movilizaciones impulsadas por CCOO para conseguir que se prorrogaran por tiempo indefinido los fondos de promoción de empleo (FPE) y evitar así que los trabajadores fueran directamente al paro.

Esta utilización de la UGT por parte del gobierno socialista, como era de esperar produjo un sentimiento de frustración en la dirección del sindicato, particularmente entre aquellos dirigentes que abogaban por una estrategia sindical autónoma e independiente. Poco a poco, quienes representaban estas posiciones de clara separación entre el partido y el sindicato, cuyo dirigente más destacado era José María Zufiaur, acabaron por controlar la cúpula de UGT y forzar la ruptura con el gobierno a partir de 1987.

Hay que reconocer que los planes de reconversión promovidos por el PSOE sirvieron para reordenar importantes sectores de la industria española, superando las tímidas reformas de los gobiernos de la UCD. Sirvieron también para sanear una parte importante de las empresas y sectores en crisis, e incluso para hacer rentable una parte de las empresas públicas que hasta entonces habian mantenido cuantiosas pérdidas. A diferencia de lo ocurrido durante los gobiernos de la transición, las inversiones dedicadas a la modernización y racionalización de equipos productivos realizadas durante la fase Solchaga fueron muy importantes, sobre todo durante el trienio 1985-1987.

El progresivo enfrentamiento de los sindicatos con el gobierno no sólo tuvo lugar por los procesos de reconversión industrial sino también por la aplicación de un tipo de política económica en clara sintonía con la que se desarrollaba en la mayoría de los países occidentales y que no se diferenciaba mucho de la que el último gobierno de la UCD había intentado poner 
en marcha y no había podido por su debilidad y por la oposición tanto del PSOE como de los sindicatos. Las prioridades en materia económica de los primeros gobiernos socialistas consistieron en reducir el déficit público, disminuir progresivamente la inflación, conterier el incremento de los salarios, aumentar la productividad y continuar con el proceso de reconversión industrial. Los resultados de esta política sólo afectaron positivamente a la inflación, que bajó seis puntos en tres años, pues el déficit no consiguió reducirse, los salarios perdieron poder adquisitivo y se perdieron medio millón más de puestos de trabajo. La tasa de paro superó el $20 \%$ en 1985 , y la población ocupada se situaba en 10,6 millones de trabajadores, dos millones menos que en 1976 y la cifra más baja de nuestra historia reciente ${ }^{8}$.

Durante 1982 y 1983, al gobierno socialista no le resultó difícil desarrollar su política económica, entre otras cosas porque aprovechó el clima de confianza, incluso de entusiasmo, que se había producido tras las llamadas «elecciones del cambio» y porque contó por una parte con el incuestionable apoyo de la UGT y por otra, con la incapacidad del PCE, que con sólo 4 diputados apenas pudo articular una oposición parlamentaria al gobierno. Sólo CCOO se atrevió a cuestionar algunos aspectos de la política económica que conducian a una reducción de las prestaciones sociales, el paso de áreas del sector público a la iniciativa privada, la imposición de topes salariales y sobre todo la política sindical discriminatoria que tuvo su máxima expresión cuando poco antes de las elecciones sindicales de 1986 el Ministerio de Trabajo entregó a UGT 4.144 millones de pesetas como compensación por el denominado "patrimonio histórico».

La dirección del PSOE estaba convencida de que la UGT no tenía más remedio que apoyar al gobierno fuera cual fuera su política. La estrecha vinculación entre el partido y el sindicato conducía inevitablemente a que si el gobierno fracasaba, arrastraría en su caida al sindicato y si por el contrario, lograba mantenerse en el poder, su éxito reforzaría al conjunto de la familia socialista ${ }^{9}$. Sin embargo, los dirigentes de la UGT no podían aceptar un planteamiento semejante, que inevitablemente reduciría su influencia sindical, dejando en manos de CCOO el trabajo de oposición al gobierno. Asi es que la UGT se enfrentaba a un grave dilema. Por una parte, no le quedaba más remedio que distanciarse progresivamente del PSOE, rompiendo con ello la tradicional relación fraternal partido-sindicato, y por otra,

\footnotetext{
8 Santos JULIA: «Ruptura de familia» en AA.VV: Memorias de la Transición, Madrid, El Pais, 1996, págs. 641-642.

9 Mariano Guindal y Rodolfo Serrano: Nicolás Redondo: El sindicalismo socialista. Unión, Madrid, 1986 , pág. 144.
} 
si se enfrentaba con el gobierno socialista corría el grave riesgo de entregarse a la política de confrontación de $\mathrm{CCOO}$ y con ello ir perdiendo sus propios referentes sindicales. Durante los años 1984-86 la UGT tuvo que mantener un difícil equilibrio entre el cada vez mayor distanciamiento con el gobierno y el progresivo acercamiento a CCOO.

A partir de 1985, comenzó a apreciarse un cambio de actitud mucho más profundo en la UGT, que por primera vez decidió enfrentarse con el gobierno y sumarse a CCOO en las movilizaciones contra la modificación del sistema de pensiones, aprobada por el Parlamento con los únicos votos del grupo socialista. La ley de Pensiones fue posiblemente la actuación más impopular y más contestada de los primeros años de gobierno socialista. La oposición al proyecto revistió una especial virulencia, que se tradujo no sólo en las movilizaciones convocadas por los sindicatos, sino también en el enfrentamiento en el seno de la familia socialista. Los dirigentes ugetistas, y también diputados del PSOE, Nicolás Redondo y Antón Saracibar votaron contra su grupo parlamentario, siguiendo los criterios del sindicato, y Antonio Rosa, senador socialista por Badajoz y responsable de la UGT en Extremadura, fue más allá y renunció a su escaño parlamentario. Este comportamiento ponía de manifiesto las profundas heridas abiertas entre la UGT y el gobierno que tardarían muchos años en cerrarse.

Durante el último trimestre de 1986, en plena campaña de las elecciones sindicales, tuvo lugar una cierta distensión en las relaciones entre UGT y el gobierno, como fruto del inicio en el proceso de devolución del patrimonio sindical, la negativa del gobierno a facilitar el despido libre, como deseaba la CEOE, y, sobre todo, la mejora de la situación económica. Sin embargo, esta situación de entendimiento se verá truncada con motivo del fracaso de un nuevo acuerdo social para 1987. Tanto la UGT como CCOO consideraron que había llegado el momento de terminar con la política de ajuste y reclamaron incrementos salariales entre el 5 y el $7 \%$, algo superiores al IPC previsto. Pero la patronal y el gobierno rechazaron estas pretensiones y finalmente no se llegó a ningún acuerdo. La falta de concertación, acompañada esta vez por un mayor entendimiento entre las centrales sindicales mayoritarias, provocó un importante aumento de la conflictividad laboral, con una pérdida de 50 millones de horas trabajadas a causa de las huelgas, y que el balance final de la negociación colectiva durante 1987 contemplara una media de incrementos salariales del $6,82 \%$, rompiéndose claramente el tope del $5 \%$ fijado por el gobierno.

Este clima de confrontación se hizo público durante un agrio debate televisado entre Nicolás Redondo y Carlos Solchaga, el 19 de febrero de 1987, en el que el dirigente ugetista le espetó al ministro: «tu problema, 
Carlos, son los trabajadores, te has equivocado de trincheras". A los pocos días se produjo la disolución de la comisión mixta de la UGT y el PSOE, lo que supuso la ruptura formal entre el partido y el sindicato. En octubre de ese mismo año, Nicolás Redondo, junto a su compañero de la comisión ejecutiva del sindicato, Antón Saracibar, dimitieron como diputados y acusaron al gobierno de realizar una política antisocial y claramente de derechas.

En la formación de la cada vez más sólida oposición sindical, la progresiva independencia de la UGT respecto al gobierno socialista fue un factor decisivo. Para entender mejor cómo se fue produciendo la disgregación de la familia socialista y los cambios estratégicos de la UGT no sólo hay que tener en cuenta las diferencias ideológicas que poco a poco iban separando al sindicato del partido, sino también otras cuestiones relacionadas con el desarrollo del sindicalismo y con la competencia entre las dos centrales mayoritarias por el reparto del espacio sindical. Hacia finales de 1986 los dirigentes de la UGT habian comprendido que ya no era posible seguir creyendo en que los éxitos electorales del PSOE, junto a la crisis profunda del comunismo, que afectó aunque en menor medida a CCOO, iban a convertir a la UGT en el sindicato hegemónico. CCOO había conseguido scbreponerse a los ataques gubernamentales y resistir a los embates de la reconversión industrial, mientras que UGT, aunque seguía siendo la primera fuerza sindical tras las elecciones sindicales de 1986, había perdido notable influencia en las grandes empresas y corría el grave riesgo de convertirse en un sindicato exclusivamente de conciliación. No es extraño, por lo tanto, que UGT, a medida que abandonaba su supeditación al partido y su estrategia de pactos, fuera recuperando su voluntad combativa y la colaboración con $\mathrm{CCOO}$ se hiciera inevitable. En febrero de 1988, las dos centrales sindicales mayoritarias llegaron a un acuerdo general sobre la necesidad de cambiar la política económica del gobierno y elaborar una plataforma unitaria para la negociación colectiva de ese año.

En ura situación de claro crecimiento económico, que se venía produciendo desde 1986, los sindicatos decidieron pasar a la ofensiva y reclamar del gobierno un giro social, consistente en incrementar el empleo, en una justa distribución de las rentas y en mayores prestaciones sociales. «Este giro en la política económica - afirmaba Nicolás Redondo- no es una demanda sindical sino que es una demanda generalizada y completamente sentida por la izquierda sociológica y por el conjunto del país» ${ }^{10}$. En los meses siguientes las relaciones gobierno-sindicatos se

10 Gaceta Sindical, n. ${ }^{\circ} 60$, marzo de 1988, pàg. 8. 
fueron deteriorando. Mientras los sindicatos acusaban sistemáticamente al gobierno de servir a los intereses de la derecha y la patronal, la plana mayor del PSOE hizo causa común con el gobierno y optaron por una actitud de provocación y claro enfrentamiento con las centrales sindicales. Las descalificaciones fueron mutuas y se volvió a un tipo de debate que recordaba al utilizado durante la campaña del referéndum de la OTAN.

La gota que colmó el vaso fue la presentación por parte del gobierno de un proyecto de ley de fomento del empleo juvenil que fue considerado por los sindicatos como una agresión a los trabajadores. El 12 de noviembre de 1988, las comisiones ejecutivas de UGT y CCOO acordaron la convocatoria de un paro general de 24 horas para el día 14 de diciembre. El llamamiento al paro se realizó desde un manifiesto, que con el título de "Juntos Podemos", reunía al resto de las centrales sindicales así como a numerosas entidades sociales, culturales e incluso organizaciones de pequeños y medianos empresarios. Junto a la inmediata retirada del plan de empleo juvenil se exigía un giro social en la política del gobierno que supusiera un incremento del subsidio de desempleo, la mejora del poder adquisitivo de los trabajadores y el aumento de la cobertura social. Estas reivindicaciones eran desde luego bastante moderadas y no presentaban ningún carácter desestabilizador. Además, los sindicatos no quisieron utilizar el término de huelga general, evitando que el paro convocado pudiera ser interpretado como una movilización de tipo político cuyo objetivo fuera la caida del gobierno. Sin embargo, para la ejecutiva del PSOE la huelga era claramente política y, cerrando filas con el ejecutivo, decidió pasar a la ofensiva contra los sindicatos, acusándoles de pretender desestabilizar la democracia y deslegitimizar al gobierno socialista. Desde los medios de comunicación, numerosos dirigentes del PSOE intentaron invalidar la acción de los sindicatos, recurriendo una vez más al caos que supondría una huelga general, que no era otra cosa que el tradicional instrumento revolucionario tantas veces preconizado por el partido comunista.

El gobierno estaba convencido de que la huelga general terminaría en un rotundo fracaso, pues aunque se respiraba un ambiente de contestación a la política gubernamental, los sindicatos eran incapaces de organizar una acción de tal envergadura. El boom de la afiliación sindical de los años $1977-78$ se habia terminado y la tasa había descendido al $16,5 \%$, la cotización de los militantes y el número de activistas era cada vez más bajo, y los aparatos sindicales dependían económicamente de las subvenciones del Estado. A pesar de esta situación, las centrales sindicales fueron capaces de movilizar no sólo al conjunto de los trabajadores sino a millones de ciudadanos que secundaron el paro contra el gobierno más 
por una actitud de contestación a la prepotencia con que el PSOE venia ocupando el poder desde 1982 que por las reivindicaciones que los sindicatos proponían.

Aunque en el éxito de la huelga general pesaron más las cuestiones sociales, los efectos políticos fueron indudables. Los sindicatos no pretendieron modificar la relación de fuerzas en el terreno político y mucho menos pedir la dimisión del gobierno, poniendo en cuestión su legitimidad. Sin embargo, el 14D fue un duro golpe para el gobierno, el más importante en sus seis años de mandato, y por el contrario un factor de estabilización y consolidación de los sindicatos. Las relaciones entre UGT y CCOO, que habian sido muy turbulentas desde los inicios de la transición, mejoraron extraordinariamente. UGT dejó de ser el sindicato del gobierno y CCOO se convirtió en un sindicato reformista, abandonó sus inclinaciones revolucionarias y fue admitido en la Confederación Europea de Sindicatos (CES).

\section{EL GIRO SOCIAL}

Tras el éxito de la huelga general del 14D, Felipe González, en vez de mantener el pulso con los sindicatos y recurrir a ia convocatoria de elecciones generales para recuperar en las urnas el apoyo perdido, decidió plegarse a las demandas que clamaban por un giro social de la política económica. Anunció rápidamente la retirada del polémico plan de empleo juvenil y a continuación llevó al Parlamento, con el acuerdo del partido popular (pacto de San Valentín), una serie de decretos, cuya aplicación supondría un aumento del gasto social en torno a los 200.000 millones. Al mismo tiempo, inició una serie de negociaciones con los sindicatos en las que se discutió fundamentaimente el incremento del gasto social y la ampliación de las prestaciones sociales a las clases menos favorecidas. Esto significaba de hecho la aplicación de una política de reparto, reconociendo que era el momento de que el esfuerzo que los trabajadores habían realizado en los años de ajuste duro sirviera para ampliar y consolidar el Estadc del Bienestar. Ya habian terminado los años de recesión y crisis económica, y desde 1986 había comenzado un proceso de recuperación sostenida. Durante 1988 la economía mundial mostró un comportamiento expansivo muy superior al que parecia posible en las estimaciones que se habían efectuado a finales de 1987. En España, durante este mismo año, el crecimiento económico alcanzó el $5 \%$, la tasa más alta de los países europeos, y el empleo también se incrementó en un 10\%; sólo la inflación sufrió un pequeño revés, que podía ser fácilmente corregido. 
Como resultado de las negociaciones y acuerdos parlamentarios que tuvieron lugar desde comienzos de 1989, el gobierno dispuso una serie de decretos y leyes, entre las que se encontraban: 1) la revalorizaron de las pensiones en un $5,8 \%$ (RD 22.3.89); 2) el aumento de la cobertura del seguro de desempleo, que pasó del $25,8 \%$ del total de paro registrado en 1988 al $63,2 \%$ en 1992, y la ampliación de la protección a los parados de larga duración y a los mayores de 45 años (RD 31.3.89) y 3) la ley de pensiones no contributivas, que supuso la entrada en la Seguridad Social de 27.000 nuevos pensionistas en 1991, cifra que alcanzó los 123.336 en 1992. Al mismo tiempo hubo un importante incremento del conjunto de pensionistas que pasaron de poco más de 5 millones en 1984 a 6,6 millones en 1992.

La puesta en vigor de toda esta legislación provocó un extraordinario aumento del gasto público de carácter social. Las prestaciones por desempleo se incrementaron en un 96\% entre 1989 y 1992, pasando de 810.000 millones a I,6 billones. Este fuerte aumento del gasto es achacable únicamente a la ampliación de la cobertura y no al incremento del paro, que se redujo desde 1988. Los gastos referidos a pensiones de la Seguridad Social sufrieron también un crecimiento desorbitado: de 1,8 billones en 1984 y 2,9 billones en 1988 se pasó a 4,8 billones en 1992. A esto habría que añadir los importantes incrementos en los gastos sanitarios de la Seguridad Social que pasaron de 847.762 millones en 1984, a 1,4 billones en 1988 y 2,4 billones en 1992. Hay que señalar, que este aumento ya se venía produciendo desde la puesta en vigor de la Ley General de Sanidad de abril de 1986, que preveía la extensión de la asistencia sanitaria al conjunto de la población y la creación de un Sistema Nacional de la Salud, cuya puesta en práctica supuso una importante reestructuración y mejora de la sanidad. Esta fuerte inyección de dinero público a los gastos sanitarios de la Seguridad Social -la aportación del Estado pasó del $14,9 \%$ en 1982 al $69,03 \%$ en 1992- provocó una situación de déficit del sistema público de salud que se arrastró en años posteriores. En conjunto, los presupuestos de todo el sistema de la Seguridad Social, cuyos epígrafes más importantes estaban dedicados a pensiones y sanidad, evolucionaron de 3 billones en 1984 a 4,8 billones en 1988, para pasar finalmente a 8,2 billones en 1992.

Otro de los grandes apartados del gasto social fue el referido a la Educación. La puesta en marcha, primero de la LRU (1983), después de la LODE (1985) y finalmente de la LOGSE (1990) trajo consigo un importante crecimiento de las inversiones en materia educativa, sobre todo entre los años 1988 a 1992. Los 930.000 millones gastados en 1984 se transformaron en 1,4 billones en 1988 para pasar finalmente a 2,6 billones en 1992. De esta última cantidad, la mayoría (1,9 billones) fue a parar a la enseñanza básica y media, y en menor medida a la enseñanza superior (365.000 millones). Aun- 
que el esfuerzo presupuestario en Educación fue realmente importante, del $3,9 \%$ del PIB en 1984 se alcanzó el 4,5\% en 1992, todavía este procentaje estaba bastante alejado de la media del gasto educativo en los países de la OCDE, que se situaba entre el $5,2 \%$ y el $5,4 \%$ del PIB.

También durante estos años (1988 a 1992) se produjeron incrementos sustanciales en otros gastos sociales, como los dedicados a viviendas, urbanismo, cultura, medio ambiente, promoción social, etc. y sobre todo un espectacular desarrollo de las inversiones públicas, dirigidas a mejorar las precarias infraestructuras del país. Las inversiones del Ministerio de Obras Públicas y Urbanismo sufrieron un incremento del 167\% entre 1982 y 1990. De acuerdo con el Plan General de Carreteras, aprobado por el Congreso en 1986, se mejoraron más de $20.000 \mathrm{~km}$. de la red y se construyeron $3.550 \mathrm{~km}$ de autovías, gracias a un fuerte incremento de los presupuestos, que pasaron de 104.000 millones en 1987 a 403.206 en 1992. Además se mejoró y modernizó la red de ferrocarriles, construyéndose el AVE Madrid-Sevilla, y hubo inversiones muy notables en obras hidraúlicas, puertos y medio ambiente, previstas en la ley de Aguas de 1985, la ley de Costas de 1988 y la ley de Puertos de 1992.

A esta política de gasto practicada desde 1989 por el gobierno socialista, se sumó la no menos importante política de inversiones públicas y gasto social de los Ayuntamientos y Comunidades Autónomas. El desarrollo del Estado de las Autonomías y la masiva transferencia de competencias y servicios del Estado a las Comunidades Autónomas, que tuvieron lugar durante estos años, provocaron que el gasto autonómico tuviera una presencia cada vez más importante en el conjunto del gasto público y que aumentara incluso en mayor porcentaje que el del Estado. Este proceso de descentralización presupuestaria dio lugar a una estructura cuasi federal, cuyo nivel de autonomía política y económica era incluso superior al de otros países, modelo de federalismo, como Canadá, Austria, Alemania, Suiza o EEUU.

Este "giro social», desarrollado entre 1989 y 1992, que trataba de reforzar la solidaridad a través, principalmente, del gasto público, significaba también de hecho la aplicación de una política típicamente socialdemócrata que se fundamentaba no sólo en la necesidad de redistribuir la renta y garantizar a todos los ciudadarios un determinado nivel de bienestar social, sino también en la confianza en la acción pública y en la intervención del Estado para conseguir estas metas ${ }^{11}$. Hay que tener en cuenta

"Antonio González Temprano (director): La política de gasto social (1984-1996). En la Administración del Estado y de las Comunidades Autónomas, Madrid, CES, 1998. 
que cuando el PSOE decide llevar a cabo este giro de carácter social, en la mayoría de los países de la OCDE y de la Unión Europea se está practicando desde mediados de los años 80 una política económica muy diferente. Por primera vez desde el final de la Segunda Guerra Mundial, el incremento de la riqueza no se traduce en el aumento del gasto público, muy al contrario, se aprovecha el crecimiento económico para acometer una serie de remodelaciones en el Estado del Bienestar (desmantelamiento parcial y selectivo), al objeto de contener la expansión del gasto y controlar el déficit.

A comienzos de 1992, esta política de gasto público ensayada por el PSOE condujo a un extraordinario incremento del déficit, precisamente en un momento en que comenzaba un nuevo ciclo económico recesivo en Occidente bajo el impacto de la Guerra del Golfo y de la reunificación alemana. La primera medida de contención del gasto social, la tomó el gobierno en abril de 1992 con un RD que recortaba las prestaciones del paro, tanto en su cuantía como en su duración, al tiempo que endurecía las condiciones para acceder al seguro de desempleo. Esta disposición, conocida como el "decretazo» y rechazada unánimemente por los sindicatos, que convocaron una huelga general en mayo de 1992, fue el primer paso del fin de la política socialdemócrata puesta en marcha en 1989, entre otras cosas, porque el gobierno debía reducir drásticamente el déficit público para tratar de cumplir las condiciones del Programa de Convergencia de la Unión Europea. 